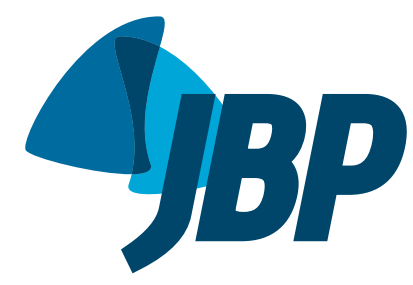

1. Departamento de Clínica Médica, Faculdade de Medicina, Universidade Federal de Minas Gerais, Belo Horizonte (MG) Brasil.

2. Ambulatório de Doenças Pulmonares Intersticiais, Hospital das Clínicas Faculdade de Medicina, Universidade Federal de Minas Gerais, Belo Horizonte (MG) Brasil

3. Hospital do Servidor Público Estadual de São Paulo, São Paulo (SP) Brasil.

4. Programa de Pós-Graduação, Assistência e Pesquisa, Ambulatório de Doencas Pulmonares Intersticiais, Faculdade de Medicina, Universidade Federal de São Paulo, São Paulo (SP) Brasil.

a. iD http://orcid.org/0000-0003-3891-875X

b. (iD http://orcid.org/0000-0002-2242-2533

c. (iD http://orcid.org/0000-0002-0352-9589

Submitted: 19 February 2018.

Accepted: 8 June 2018.

Study carried out at the Hospital do Servidor Público Estadual de São Paulo, São Paulo (SP) Brasil, and at the Hospital das Clínicas, Faculdade de Medicina, Universidade Federal de Minas Gerais, Belo Horizonte (MG) Brasil.

\section{Six-minute walk distance and survival time in patients with idiopathic pulmonary fibrosis in Brazil}

\author{
Eliane Viana Mancuzo ${ }^{1,2, a}$, Maria Raquel Soares ${ }^{3, b}$, \\ Carlos Alberto de Castro Pereira ${ }^{4, c}$
}

\begin{abstract}
Objective: To determine the cut-off point for the six-minute walk distance (6MWD) that indicates lower survival time in patients with idiopathic pulmonary fibrosis (IPF) in Brazil. Methods: This was retrospective study carried out in two referral centers for IPF. The 6MWT was performed twice, considering the highest value of the 6MWD. Various cutoff points were estimated, in absolute values and in percentage of predicted values, using ROC curves, the Kaplan-Meier method, and data from other studies. Results: The sample comprised 70 patients with IPF. The mean age was $71.9 \pm 6.4$ years, and 50 patients $(71.4 \%)$ were male. The mean FVC was $76.6 \pm 18.2 \%$ of predicted value. The mean $\mathrm{SpO}_{2}$ at rest before and after $6 \mathrm{MWT}$ were $93.8 \pm 2.5 \%$ and $85.3 \pm 6.5 \%$, respectively. The median survival time was 44 months (95\% Cl: $37-51$ months). The mean 6MWD was $381 \pm 115 \mathrm{~m}(79.2 \pm 24.0 \%$ of predicted). After the analyses, the best cut-off points for estimating survival were 6MWD $<330 \mathrm{~m}$ and $<70 \%$ of predicted. The median survival time of patients with a 6MWD < $330 \mathrm{~m}$ was 24 months $195 \% \mathrm{Cl}$ : 3-45 months), whereas that of those with a $6 \mathrm{MWD} \geq 330 \mathrm{~m}$ was 59 months $(95 \% \mathrm{Cl}$ : 41-77 months; $p=0.009$ ). Similarly, the median survival times of those with a 6MWD $<70 \%$ and $\geq 70 \%$ of predicted, respectively, were 24 months (95\% Cl: $13-35$ months) and 59 months (95\% Cl: 38-80 months; $p=0.013$ ). Cox multivariate regression models including age, sex, smoking status, $\mathrm{SpO}_{2}$ at the end of the 6MWT, and FVC\% showed that 6MWD remained significantly associated with survival $(p=0.003)$. Conclusions: Values of $6 \mathrm{MWD}<330 \mathrm{~m}$ and $<70 \%$ of predicted value were associated with lower survival time in IPF patients in Brazil.
\end{abstract}

Keywords: Lung diseases, interstitial; Pulmonary fibrosis; Exercise tolerance.

\section{INTRODUCTION}

Idiopathic pulmonary fibrosis (IPF) is an interstitial lung disease (ILD) of unknown etiology, which is accompanied by functional loss, progressive dyspnea, and impaired quality of life. ${ }^{(1)}$ The median survival, prior to the therapeutic era, was between 2 and 4 years. ${ }^{(2)}$ The clinical course of IPF is highly variable. This great variability in the evolution of IPF makes its staging and prognosis a challenge. Some individual predictors of survival have already been established, such as increased dyspnea on initial presentation, digital clubbing, pulmonary hypertension, increased extent of fibrosis on HRCT scans, and increased number of hospital admissions, mainly due to respiratory failure. ${ }^{(3,4)}$ Lung function plays a key role in prognostic evaluation. ${ }^{(3,5)}$ Baseline values of FVC $<70 \%$, DLCO < 40\%, and $\mathrm{SpO}_{2}<89 \%$ during physical exertion indicate worse survival. ${ }^{(6-9)}$

Another way of assessing prognosis during the initial evaluation includes the use of predictive composite statistical models or scoring systems that combine functional variables, clinical data, and other prognostic tests. These models are more effective in predicting survival than are individual variables. Various studies have appeared in the past years with this proposal, some even emphasizing the six-minute walk distance (6MWD) as having prognostic value. ${ }^{(10-15)}$

The six-minute walk test (6MWT) is, by definition, an endurance test, i.e., a submaximal test. For most patients with mild-to-moderate cardiopulmonary disease, the metabolic demand is lower than is the maximum demand obtained from an incremental test, and, therefore, maximum limits are seldom reached. However, for a group of patients with more severe disease, such as in patients with interstitial lung disease, the 6MWT can be considered a "near-maximal" test, because the metabolic/energy expenditure during the test approaches the maximum limit, due to the symptoms of these patients. ${ }^{(16)}$

An evaluation of a global integrated response of all the systems involved in performing the exercise (pulmonary system, cardiovascular system, systemic/peripheral circulation, blood, neuromuscular unit, and muscle metabolism) is provided by the 6MWT. ${ }^{(17-20)}$ The 6MWT is extremely useful in clinical practice for the evaluation of patients with various advanced cardiopulmonary 
conditions, and it has been included in clinical trials on IPF treatment for the determination of outcomes. ${ }^{(19,21)}$

Three studies have evaluated baseline 6MWD as an independent variable associated with mortality in patients with IPF, suggesting cut-off values of $181 \mathrm{~m}$

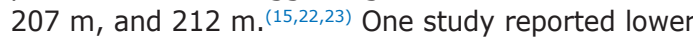
baseline 6MWD results in patients with ILDs and pulmonary hypertension, who, consequently, had a worse prognosis. ${ }^{(24)}$ A post-hoc analysis of a clinical trial( $^{(25)}$ showed that baseline 6MWD and a decrease in 6MWD at week 24 were significantly associated with 1-year mortality, despite the poor correlation between 6MWD results and other pulmonary function test measurements. A subsequent analysis using the same database showed that baseline 6MWD $<250 \mathrm{~m}$ was associated with a 1-year mortality rate twice as high (hazard ratio $=2.12$ ). ${ }^{(26)}$

IPF usually affects older patients, who may present with various comorbidities. The prevalence of cardiovascular disease in patients with IPF can reach up to $26 \%$ and contribute to $10 \%$ of the mortality rate. ${ }^{(27)}$

In a recent review, the authors have made relevant considerations on the relationship between 6MWD and mortality, emphasizing the importance of 6MWD in the evaluation of comorbidities and quality of life in patients with IPF. ${ }^{(28)}$ In Brazil, healthy individuals older than 40 years of age walk greater distances in the 6MWT when compared with individuals in other countries. ${ }^{(29)}$

The objective of the present study was to determine the cut-off point for 6MWD that indicates lower survival in patients with IPF in a cohort of patients in Brazil.

\section{METHODS}

This was a retrospective study involving patients from two referral centers for the treatment of ILDs in Brazil, namely, Ambulatório de Doenças Pulmonares Intersticiais (Interstitial Lung Disease Outpatient Clinic), Hospital das Clínicas, Faculdade de Medicina, Universidade Federal de Minas Gerais, located in the city of Belo Horizonte, Brazil, and Ambulatório de Doenças Pulmonares Intersticiais, Faculdade de Medicina, Universidade Federal de São Paulo, located in the city of São Paulo, Brazil, between June 4, 1993 and September 30, 2017. The date of diagnosis was used as the initial date for the analysis of survival.

The study was approved by the research ethics committee of the coordinating center (CAAE protocol no. 44843215.50000.5149).

The diagnosis of IPF was performed based on recommendations from an international guideline. ${ }^{(2)}$ All of the cases were reviewed by two pulmonologists and one radiologist, and biopsies were reviewed by a pathologist with extended experience in lung biopsies. The three professionals are specialists in ILDs.

We excluded patients with an $\mathrm{SpO}_{2}<89 \%$ at rest on room air; patients with degenerative locomotor or neuromuscular diseases or with functional limitations that prevented test performance; patients with a history of acute myocardial infarction within the last month; and patients with decompensated heart failure, unstable angina, syncope, or cardiac arrhythmia.

The date of diagnosis, sex, age, duration of symptoms, history of smoking, and perception of dyspnea (determined by the modified scale of the Medical Research Council)(30) were collected from the medical records and inserted into a specific form for the systematic evaluation of patients with ILD. (29)

The 6MWT was performed in a 30-m corridor, using a portable oximeter (Nonin Medical, Inc., Plymouth, MN, USA), following international recommendations. $(17,19,20)$ All patients performed two tests, with a minimum time interval of $30 \mathrm{~min}$; verbal encouragement was given every minute. The following parameters were recorded at the beginning and at the end of the tests: $H R, R R$, perception of dyspnea by the Borg scale score (data not shown), $\mathrm{SpO}_{2}$ measured by pulse oximetry, and 6MWD, the latter being expressed in absolute values and in percentage of predicted values, which were calculated by means of the reference equation proposed by Soares et al. for the Brazilian population. (31)

Although this was a retrospective and multicenter study, the same type of equipment was used in both centers: Collins CPL system (Ferraris Respiratory, Louisville, CO, USA). Acceptability and reproducibility criteria for pulmonary function tests followed the recommendations by the American Thoracic Society. (32) The results were described as absolute values and as percentage of predicted values for the Brazilian population. ${ }^{(33)}$ The studied variables were $\mathrm{FVC}, \mathrm{FEV}_{1}$, and $\mathrm{FEV}_{1} / \mathrm{FVC}$ ratio. DLCO measurements were performed using the single-breath method. The predicted values suggested by Crapo et al. were used. ${ }^{(34)}$

Continuous variables were presented as means and standard deviations or medians and minimum and maximum values, when indicated; categorical variables were described as proportions. Various cut-off points, including those suggested in the literature, were tested by the Kaplan-Meier method and ROC curves to identify the cut-off point with the highest discriminatory value, both for absolute values and percentage of predicted values for 6MWD. Using the ROC curves, sensitivity vs. 1 - specificity points closer to $10 \%$ were selected, because many false-positive results can be obtained from points with the highest sum of sensitivity and specificity. These cut-off points were similar to those observed by testing various cut-off points using the Kaplan-Meier curves, the highest value being determined for the log-rank test.

Survival curves were constructed using the KaplanMeier method. Cox multivariate regression models were analyzed in order to measure the associations between mortality and 6MWD, taking into account the following variables: age, sex, smoking status, and FVC in \% of predicted value. A p-value $<0.05$ was considered statistically significant for all tests. All the analyses were performed using the statistical package 
IBM SPSS Statistics, version 21.0 (IBM Corporation, Armonk, NY, USA).

\section{RESULTS}

A total of 70 patients were included in the study. The mean age was $71.9 \pm 6.5$ years. Most of the patients were male $(71.4 \%)$ and smokers or former smokers $(71.4 \%)$. The diagnosis of IPF was reached by clinical data, in $87.1 \%$ of the sample, and by surgical lung biopsy, in $22.9 \%$. The mean 6MWD was $380 \pm$ $115 \mathrm{~m}$. The median follow-up time was 37.6 months. Clinical and functional characteristics are summarized in Tables 1 and 2.

The median survival was 44 months (95\% CI: $37-51$ months). After various analyses, the best cut-off points for estimating survival based on 6MWD results were $330 \mathrm{~m}$ and $70 \%$ of predicted values. Both ROC curves were significant. The area under the curve for 6MWD in absolute values and in percentage of predicted value were, respectively, $0.70(p=0.008)$ and 0.65 $(p=0.047)$. Sensitivity for the selected absolute cut-off point (330 m) was $39 \%$, and 1 - specificity (false positive) was $13 \%$, with a likelihood ratio of 3.00. For the cut-off point of $70 \%$ of the predicted value, sensitivity was $38 \%$, and false-positive value was $13 \%$, with a likelihood ratio of 2.92 , i.e., they are almost identical.

Of the 70 patients in the sample, 21 (30\%) had a 6 MWD $<70 \%$ of predicted and $22(31.4 \%)$ had a 6 MWD $<330 \mathrm{~m}$. The median survival time of the patients with a 6MWD $<330$ m was 24 months $(95 \%$ CI: 3-45 months), whereas the median survival time of those with a 6MWD $\geq 330$ m was 59 months ( $95 \% \mathrm{CI}$ : 38-80 months; log rank: 6.78; $p=0.009$; Figure 1). Similarly, the median survival time of patients with a $6 \mathrm{MWD}<70 \%$ of predicted value was 24 months (95\% CI: $13-35$ months), and that of those with a 6MWD $\geq 70 \%$ of predicted value was 59 months $(95 \% \mathrm{CI}$ : 38-80 months; log-rank: 6.17; $\mathrm{p}=0.013$; Figure 2).

Table 1. Clinical characteristics of patients with interstitial pulmonary fibrosis included in the study $(\mathrm{N}=70){ }^{a}$

\begin{tabular}{lc}
\multicolumn{1}{c}{ Variable } & Result \\
Center & \\
$\quad$ HSPE/SP & $39(57)$ \\
$\quad$ HC-UFMG & $31(43)$ \\
Age, years & $71.9 \pm 6.5$ \\
Males & $50(71.4)$ \\
Smoking status & \\
$\quad$ Never smoker & $20(28.6)$ \\
$\quad$ Smoker or former smoker & $50(71.4)$ \\
Diagnosis & \\
$\quad$ Clinical & \\
$\quad$ Biopsy & $61(87.1)$ \\
Survival time, months & $9(12.9)$ \\
Follow-up period. months & $44[37-51]$ \\
\hline
\end{tabular}

HSPE/SP: Hospital do Servidor Público Estadual de São Paulo; HC-UFMG: Hospital das Clínicas da Universidade Federal de Minas Gerais. ${ }^{a}$ Values expressed in n (\%), mean \pm SD or median [minimum-maximum].
The analysis of Cox multivariate regression models, considering age, sex, smoking status, $\mathrm{SpO}_{2}$ at the end of the $6 \mathrm{MWT}$, and FVC\% showed that $6 \mathrm{MWD}$ remained significantly associated with survival $(p=0.003)$.

\section{DISCUSSION}

The present study demonstrated that a 6 MWD $<330$ $\mathrm{m}$ or $<70 \%$ of the predicted value was associated with a median survival time of only 24 months in patients with IPF in Brazil.

The 6MWT has been used as a valid, simple, and reliable instrument for the evaluation of exercise capacity in patients with chronic respiratory diseases, including IPF. ${ }^{(15,22,23,35)}$ In addition, the 6MWT is a better predictor of exercise capacity when compared with functional tests (spirometry) and quality of life tests. ${ }^{(18)}$

The 6MWT is well standardized and easily reproduced, has low costs, and is safe. ${ }^{(18)}$ However, it can be influenced by the size of the corridor, as well as by baseline hypoxemia, reduced muscle strength, sedentary lifestyle, and associated heart and muscle disease of the patient. These factors should be taken into consideration in the interpretation of 6MWT results. ${ }^{(18)}$ In order to reduce the learning effect, two tests were performed in our study, the highest value obtained being selected and compared with the predicted result derived from one of the reference equations proposed for the Brazilian population. ${ }^{(17,18,31)}$

The 6MWT has an advantage over static measures of lung function, because it provides a functional measure of the general cardiopulmonary reserve of the patient and can incorporate other important prognostic parameters for evaluation.

Andersen et al. ${ }^{(24)}$ studied 212 patients with IPD and found that a 6MWD $<345 \mathrm{~m}$ was independently associated with the presence of pulmonary hypertension. In our results, 6MWD $<330 \mathrm{~m}(\mathrm{p}=0.009)$ or $<70 \%$ of predicted $(p=0.013$ ) was associated with a three-fold

Table 2. Functional characteristics of patients with interstitial pulmonary fibrosis included in the study $(\mathrm{N}=70) .^{\text {a }}$

\begin{tabular}{lc}
\multicolumn{1}{c}{ Variable } & Result \\
Spirometry & \\
FVC, L & $2.54 \pm 0.84$ \\
FVC, \% predicted & $76.61 \pm 18.23$ \\
FEV $_{1}, \mathrm{~L}$ & $2.11 \pm 0.57$ \\
$\mathrm{FEV}_{1}, \%$ predicted & $75.74 \pm 21.35$ \\
$\mathrm{FEV}_{1} / \mathrm{FVC}, \%$ & $83.09 \pm 7.83$ \\
$\mathrm{DLCO}, \mathrm{L}$ & $12.6 \pm 4.09$ \\
$\mathrm{DLCO}, \%$ predicted & $52.7 \pm 13.9$ \\
6MWT & \\
6MWD, m & $380 \pm 115$ \\
6MWD, \% $\mathrm{predicted}^{-}$ & $79.2 \pm 24.0$ \\
Pre-6MWT SpO & $93.81 \pm 2.47$ \\
Post-6MWT $\mathrm{SpO}_{2}$ & $85.29 \pm 6.53$ \\
\hline
\end{tabular}

6MWT: six-minute walk test; 6MWD: six-minute walk distance. ${ }^{a}$ Values expressed in mean \pm SD. 


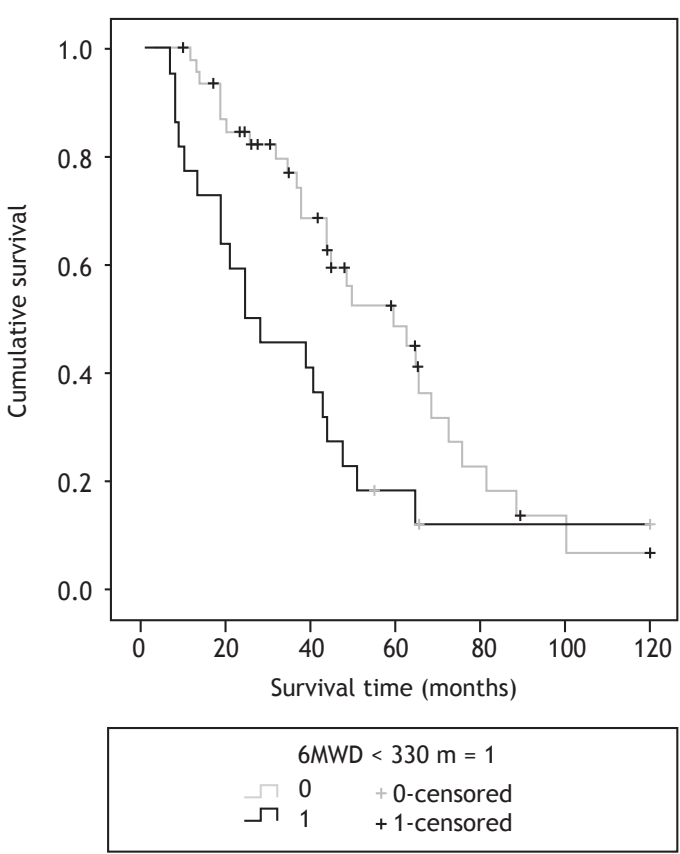

Figure 1. Survival time in patients with interstitial lung fibrosis according to the six-minute walk test distance $(6 \mathrm{MWD})<330 \mathrm{~m}$ or $\geq 330 \mathrm{~m}$ (log-rank test: $6.78 ; \mathrm{p}=$ 0.009).

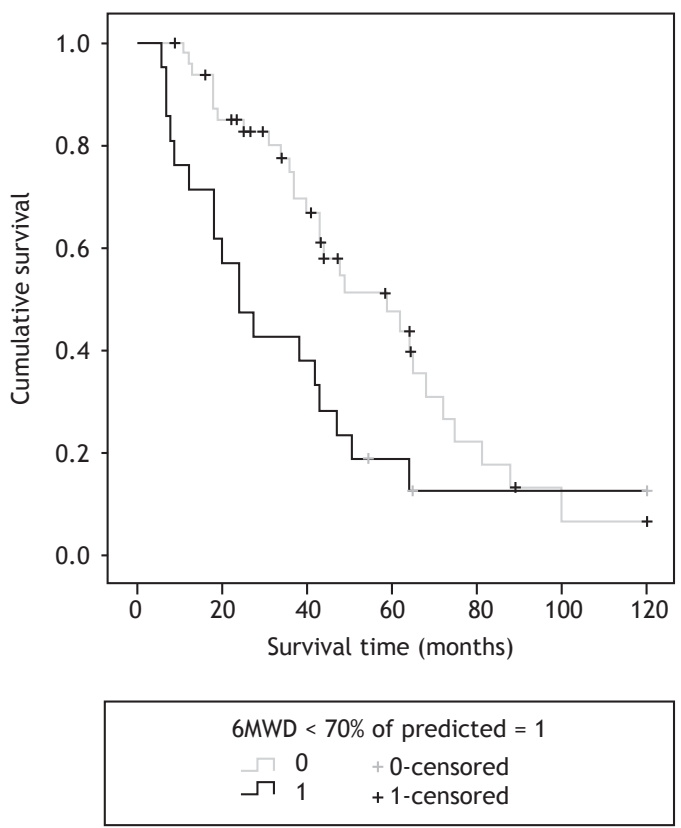

Figure 2. Survival time in patients with interstitial lung fibrosis according to the six-minute walk distance (6MWD) $<70 \%$ or $\geq 70 \%$ of predicted values (log-rank test: 6.17 ; $\mathrm{p}=0.013)$.

increased risk of mortality and decreased survival; however, the presence of pulmonary hypertension was not evaluated. Lettieri et al., ${ }^{(15)}$ in a study involving 81 patients (48 survivors and 33 nonsurvivors on a waiting list for lung transplantation), found that the 6MWD was significantly higher in the survivors than in the nonsurvivors (407 m vs. $181 \mathrm{~m}$; $\mathrm{p}<0.005$ ). In that study, $38 \%$ of patients were on oxygen therapy, and the 1 -year mortality rate was $41 \%$, compared with $14 \%$ in the present sample; this difference might be explained by the inclusion of more severe patients on the waiting list for transplantation in that study. ${ }^{(15)}$ Another study involving 454 patients with IPF who were also on the waiting list for lung transplantation demonstrated that patients with a 6MWD $<207 \mathrm{~m}$ were associated with a four-fold mortality risk at six months when compared with those with a 6MWD $\geq$ $207 \mathrm{~m}$, regardless of gender, age, and baseline FVC.(23) In that study, ${ }^{(23)}$ the patients were younger (55 \pm 9 years) and presented with more severe disease (FVC $=47 \pm 14 \%$ ) when compared with the patients in the present study, who had a higher mean age (71.9 \pm 6.5 years) and higher mean FVC\% (76.61 $\pm 18.23 \%)$.

Caminati et al. ${ }^{(22)}$ showed that a 6 MWD $<212 \mathrm{~m}$ was associated with shorter survival time (log-rank test; $p$ $<0.036)$ in a group of 44 patients with IPF. The median 6MWD was 375 m in survivors, compared with 200 m in nonsurvivors. The median length of follow-up was 19.8 months (3.2-46.4 months). (22) Unlike our results, which showed a frequency of $71 \%$ of male patients, in the study by Caminati et al., (22) that frequency was $52 \%$; however, FVC\% was comparable in both studies ( $76 \%$ vs. $74 \%$ ). It is postulated that male gender is a factor associated with higher 6MWD. ${ }^{(29)}$

The Latin-American Thoracic Association demonstrated that Latin-American samples (including a Brazilian one in the city of São Paulo) presented with higher values of 6MWD when compared with those found in countries in the northern hemisphere (Spain and the USA), ${ }^{(29)}$ a finding that might be related to the characteristics of COPD patients with similar degrees of functional loss: such patients in Brazil tend to walk longer and more often than do patients in the USA. Therefore, there is still no definitive answer regarding 6MWD values that undoubtedly characterize and qualify the functional incapacity of patients with chronic lung diseases, except in extreme cases. In this context, we decided to evaluate the 6MWD in a cohort of patients with IPF in Brazil to determine whether this could be as high as in patients with $\operatorname{COPD}^{(29)}$; our hypothesis was confirmed. The geographic variations found here can not be explained by anthropometric factors. It is speculated that other factors, such as walking speed or cultural aspects related to lifestyle, mood, attitudes, and motivation of these individuals, might have influenced the 6MWD results. However, further studies exploring the physiological variables and their responses to exercise are necessary. ${ }^{(29)}$

IPF is a progressive disease with a very poor prognosis. A practical application of the results in our study would be the immediate referral of patients with a 6MWD < $330 \mathrm{~m}$ or $<70 \%$ of predicted to be specifically assessed for lung transplantation. The median survival time in patients with a 6MWD $<330$ m was 24 months in the present study. The mean time on the waiting list for 
lung transplantation in the state of São Paulo, Brazil, is 18 months. ${ }^{(35)}$

Some limitations of the present study should be considered. The first one is related to the sample, which was relatively small, but equivalent to those in other studies in the literature. ${ }^{(16,22,36)}$ However, our median follow-up period was 38 months, which greatly strengthens the present study, when compared with a follow-up period of 13 months in studies with larger samples. ${ }^{(26,35)}$ Another limitation is related to the exclusion of patients with $\mathrm{SpO}_{2}<89 \%$ at rest and of all users of supplemental oxygen, which determines a worse prognosis in such patients. In addition, ours was a retrospective study; however, the variables were collected by experienced and trained teams, by means of a standardized and structured protocol that made it possible to review the diagnosis of IPF carefully. Because the study was performed in only two centers, it was also possible to compare and ensure that the methodology used to perform the 6MWT in these centers was identical.

In conclusion, a 6 MWD $<330 \mathrm{~m}$ or $<70 \%$ of the predicted value is significantly associated with a shorter survival time in patients with IPF in Brazil.

\section{REFERENCES}

1. Raghu G, Rochwerg B, Zhang Y, Garcia CA, Azuma A, Behr J, et al An Official ATS/ERS/JRS/ALAT Clinical Practice Guideline: Treatment of Idiopathic Pulmonary Fibrosis. An Update of the 2011 Clinica Practice Guideline. Am J Respir Crit Care Med. 2015;192(2):e3-19. https://doi.org/10.1164/rccm.201506-1063ST

2. Raghu G, Collard HR, Egan JJ, Martinez FJ, Behr J, Brown KK, et al. An official ATS/ERS/JRS/ALAT statement: idiopathic pulmonary fibrosis: evidence-based guidelines for diagnosis and management. Am J Respir Crit Care Med. 2011;183(6):788-824. https://doi. org/10.1164/rccm.2009-040GL

3. Ley B, Collard HR, King TE. Clinical course and prediction of survival in idiopathic pulmonary fibrosis. Am J Respir Crit Care Med. 2011;183(4):431-40. https://doi.org/10.1164/rccm.201006-0894Cl

4. Brown AW, Fischer CP, Shlobin OA, Buhr RG, Ahmad S, Weir NA, et al. Outcomes after hospitalization in idiopathic pulmonary fibrosis: a cohort study. Chest. 2015;147(1):173-179. https://doi.org/10.1378/ chest.13-2424

5. Nathan SD, Meyer KC. IPF clinical trial design and endpoints. Curr Opin Pulm Med. 2014;20(5):463-71. https://doi.org/10.1097/ MCP.0000000000000091

6. Nathan SD, Shlobin OA, Weir N, Ahmad S, Kaldjob JM, Battle E, et al. Long-term course and prognosis of idiopathic pulmonary fibrosis in the new millennium. Chest. 2011;140(1):221-229. https://doi. org/10.1378/chest.10-2572

7. Mogulkoc N, Brutsche MH, Bishop PW, Greaves SM, Horrocks AW Egan $\mathrm{JJ}$; et al. Pulmonary function in idiopathic pulmonary fibrosis and referral for lung transplantation. Am J Respir Crit Care Med. 2001;164(1):103-8. https://doi.org/10.1164/ajrccm.164.1.2007077

8. Lama VN, Flaherty KR, Toews GB, Colby TV, Travis WD, Long Q, et al. Prognostic value of desaturation during a 6-minute walk test in idiopathic interstitial pneumonia. Am J Respir Crit Care Med. 2003;168(9):1084-90. https://doi.org/10.1164/rccm.200302-2190C

9. Stephan S, de Castro Pereira CA, Coletta EM, Ferreira RG, Otta JS, Nery LE. Oxygen desaturation during a 4-minute step test: predicting survival in idiopathic pulmonary fibrosis. Sarcoidosis Vasc Diffuse Lung Dis. 2007;24(1):70-6.

10. Wells AU, Desai SR, Rubens MB, Goh NS, Cramer D, Nicholson AG et al. Idiopathic pulmonary fibrosis: a composite physiologic index derived from disease extent observed by computed tomography. Am J Respir Crit Care Med. 2003;167(7):962-9. https://doi. org/10.1164/rccm.2111053

11. du Bois RM, Weycker D, Albera C, Bradford WZ, Costabel U, Kartashov $A$, et al. Ascertainment of individual risk of mortality for patients with idiopathic pulmonary fibrosis. Am J Respir Crit Care Med. 2011;184(4):459-66. https://doi.org/10.1164/rccm.201011$17900 \mathrm{C}$

12. Ley $B$, Collard HR. Risk prediction in idiopathic pulmonary fibrosis. Am J Respir Crit Care Med. 2012;185(1):6-7. https://doi.org/10.1164/ rccm.201111-1960ED

13. Soares MR, Pereira C, Ferreira R, Nei Aparecida Martins Coletta E, Silva Lima M, Muller Storrer K. A score for estimating survival in idiopathic pulmonary fibrosis with rest $\mathrm{SpO} 2>88$. Sarcoidosis Vasc Diffuse Lung Dis. 2015;32(2):121-8

14. Mura M, Porretta MA, Bargagli E, Sergiacomi G, Zompatori M, Sverzellati N, et al. Predicting survival in newly diagnosed idiopathic pulmonary fibrosis: a 3-year prospective study. Eur Respir J.
2012;40(1):101-9. https://doi.org/10.1183/09031936.00106011

15. Lettieri CJ, Nathan SD, Browning RF, Barnett SD, Ahmad S, Shor AF. The distance-saturation product predicts mortality in idiopathic pulmonary fibrosis. Respir Med. 2006;100(10):1734-41. https://doi. org/10.1016/j.rmed.2006.02.004

16. Eaton T, Young P, Milne D, Wells AU. Six-minute walk, maximal exercise tests: reproducibility in fibrotic interstitial pneumonia. Am J Respir Crit Care Med. 2005;171(10):1150-7. https://doi.org/10.1164/ rccm.200405-5780C

17. Enright PL. The six-minute walk test. Respir Care. 2003;48(8):783-5

18. Singh SJ, Puhan MA, Andrianopoulos V, Hernandes NA, Mitchell $K E$, Hill CJ, et al. An official systematic review of the European Respiratory Society/American Thoracic Society: measurement properties of field walking tests in chronic respiratory disease. Eur Respir J. 2014:44(6):1447-78

19. Holland AE, Spruit MA, Troosters T, Puhan MA, Pepin V, Saey $D$, et al. An official European Respiratory Society/American Thoracic Society technical standard: field walking tests in chronic respiratory disease. Eur Respir J. 2014;44(6):1428-46. https://doi. org/10.1183/09031936.00150314

20. ATS Committee on Proficiency Standards for Clinical Pulmonary Function Laboratories. ATS statement: guidelines for the six-minute walk test. Am J Respir Crit Care Med. 2002;166(1):111-7. https://doi. org/10.1164/ajrccm.166.1.at1102

21. King CS, Nathan SD. Idiopathic pulmonary fibrosis: effects and optimal management of comorbidities. Lancet Respir Med. 2017;5(1):72-84. https://doi.org/10.1016/S2213-2600(16)30222-3

22. Caminati A, Bianchi A, Cassandro R, Mirenda MR, Harari S. Walking distance on 6-MWT is a prognostic factor in idiopathic pulmonary fibrosis. Respir Med. 2009;103(1):117-23. https://doi.org/10.1016/j. rmed.2008.07.022

23. Lederer DJ, Arcasoy SM, Wilt JS, D'Ovidio F, Sonett JR, Kawut SM. Six-minute-walk distance predicts waiting list survival in idiopathic pulmonary fibrosis. Am J Respir Crit Care Med. 2006;174(6):659-64. https://doi.org/10.1164/rccm.200604-5200C

24. Andersen CU, Mellemkjær S, Hilberg O, Nielsen-Kudsk JE, Simonsen U, Bendstrup E. Pulmonary hypertension in interstitial lung disease: prevalence, prognosis and 6 min walk test. Respir Med. 2012;106(6):875-82. https://doi.org/10.1016/j.rmed.2012.02.015

25. du Bois RM, Weycker D, Albera C, Bradford WZ, Costabel U, Kartashov $A$, et al. Six-minute-walk test in idiopathic pulmonary fibrosis: test validation and minimal clinically important difference. Am J Respir Crit Care Med. 2011;183(9):1231-7. https://doi. org/10.1164/rccm.201007-11790C

26. du Bois RM, Albera C, Bradford WZ, Costabel U, Leff JA, Noble PW, et al. 6-minute walk test distance is an independent predicto of mortality in patients with idiopathic pulmonary fibrosis. Eur Respir J. 2014;43(5):1421-9. https://doi.org/10.1183/09031936.00131813

27. King C, Nathan SD. Identification and treatment of comorbidities in idiopathic pulmonary fibrosis and other fibrotic lung diseases. Curr Opin Pulm Med. 2013;19(5):466-73. https://doi.org/10.1097/ MCP.0b013e328363f460

28. Brown AW, Nathan SD. The Value and Application of the 6-MinuteWalk Test in Idiopathic Pulmonary Fibrosis. Ann Am Thorac Soc 2018;15(1):3-10. https://doi.org/10.1513/AnnalsATS.201703-244FR

29. Casanova C, Celli BR, Barria P, Casas A, Cote C, de Torres JP, et 
al. The 6-min walk distance in healthy subjects: reference standards from seven countries. Eur Respir J. 2011;37(1):150-6. https://doi. org/10.1183/09031936.00194909

30. Celli BR, MacNee W: ATS/ERS Task Force.. Standards for the diagnosis and treatment of patients with COPD: a summary of the ATS/ERS position paper. Eur Respir J. 2004;23(6):932-46. https://doi. org/10.1183/09031936.04.00014304

31. Soaresa MR, Pereira CA. Six-minute walk test: reference values for healthy adults in Brazil. J Bras Pneumol. 2011;37(5):576-83.

32. Pellegrino R, Viegi G, Brusasco V, Crapo RO, Burgos F, Casaburi $R$, et al. Interpretative strategies for lung function tests. Eur Respir $\mathrm{J}$. 2005;26(5):948-68. https://doi.org/10.1183/09031936.05.00035205

33. Pereira CA, Sato T, Rodrigues SC. New reference values for forced spirometry in white adults in Brazil. J Bras Pneumol. 2007;33(4):397-
406. https://doi.org/10.1590/S1806-37132007000400008

34. Crapo RO, Morris AH. Standardized single breath normal values for carbon monoxide diffusing capacity. Am Rev Respir Dis. 1981;123(2):185-9

35. Nathan SD, du Bois RM, Albera C, Bradford WZ, Costabel U, Kartashov $\mathrm{A}$, et al. Validation of test performance characteristics and minimal clinically important difference of the 6-minute walk test in patients with idiopathic pulmonary fibrosis. Respir Med. 2015;109(7):914-22. https://doi.org/10.1016/j.rmed.2015.04.008

36. Kawut SM, O'Shea MK, Bartels MN, Wilt JS, Sonett JR, Arcasoy $\mathrm{SM}$. Exercise testing determines survival in patients with diffuse parenchymal lung disease evaluated for lung transplantation. Respir Med. 2005;99(11):1431-9. https://doi.org/10.1016/i. rmed.2005.03.007 